\title{
Competitive amplification of differentially melting amplicons (CADMA) improves KRAS hotspot mutation testing in colorectal cancer
}

\author{
Lasse Sommer Kristensen ${ }^{1 *}$, Tina Ellegaard Kjeldsen ${ }^{1}$, Henrik Hager ${ }^{2}$ and Lise Lotte Hansen ${ }^{1}$
}

\begin{abstract}
Background: Cancer is an extremely heterogeneous group of diseases traditionally categorized according to tissue of origin. However, even among patients with the same cancer subtype the cellular alterations at the molecular level are often very different. Several new therapies targeting specific molecular changes found in individual patients have initiated the era of personalized therapy and significantly improved patient care. In metastatic colorectal cancer (mCRC) a selected group of patients with wild-type KRAS respond to antibodies against the epidermal growth factor receptor (EGFR). Testing for KRAS mutations is now required prior to anti-EGFR treatment, however, less sensitive methods based on conventional PCR regularly fail to detect KRAS mutations in clinical samples.

Methods: We have developed sensitive and specific assays for detection of the seven most common KRAS mutations based on a novel methodology named Competitive Amplification of Differentially Melting Amplicons (CADMA). The clinical applicability of these assays was assessed by analyzing 100 colorectal cancer samples, for which KRAS mutation status has been evaluated by the commercially available TheraScreen ${ }^{\circledR}$ KRAS mutation kit.

Results: The CADMA assays were sensitive to at least 0.5\% mutant alleles in a wild-type background when using 50 nanograms of DNA in the reactions. Consensus between CADMA and the TheraScreen kit was observed in 96\% of the colorectal cancer samples. In cases where disagreement was observed the CADMA result could be confirmed by a previously published assay based on TaqMan probes and by fast COLD-PCR followed by Sanger sequencing.

Conclusions: The high analytical sensitivity and specificity of CADMA may increase diagnostic sensitivity and specificity of KRAS mutation testing in $\mathrm{mCRC}$ patients.
\end{abstract}

Keywords: Colorectal Cancer, EGFR, KRAS, DNA mutational analyses, CADMA

\section{Background}

Cancer is the result of a somatic microevolution in which cells acquire specific growth advantages through a stepwise accumulation of mitotically heritable changes in the function of cancer related genes, which may be oncogenes, tumor suppressor genes, and DNA repair genes. Most cancers are extremely complex at the molecular level, and two patients suffering from the same cancer disease may have acquired very different cellular alterations. Consequently, there is a huge potential in

\footnotetext{
* Correspondence: lasse@hum-gen.au.dk

${ }^{1}$ Department of Biomedicine, University of Aarhus, Bartholin Building,

Wilhelm Meyers Allé 4, DK-8000 Aarhus C, Denmark

Full list of author information is available at the end of the article
}

individualizing patient treatment using molecular biomarkers as predictors for response or non-response to targeted therapy.

New therapies targeting specific molecular changes in tumors of individual patients have started to introduce a paradigm shift for cancer treatment. Most cancer patients are now tested for one or more molecular biomarkers in order to determine optimal treatment strategies for the individual patient [1].

Activating somatic mutations in the KRAS oncogene is an example of a biomarker, which predicts non-response to therapies targeting the epidermal growth factor receptor (EGFR) in metastatic Colorectal Cancer (mCRC) $[2,3]$. EGFR and KRAS are part of the same signaling

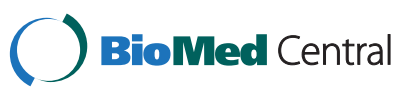


pathway, and EGFR overexpression as well as activating KRAS mutations contribute to development and progression of several human cancers, including CRC. An important feature of mutant KRAS is its ability to transmit growth promoting signals independent of EGFR activation. This is the biological explanation why antiEGFR treatment fails to inhibit progression of KRAS mutated tumors. Activating mutations in KRAS are most often found in a mutation hotspot comprising codon 12 and 13 of exon 2. Therefore, the U.S. Food and Drug Administration (FDA) and the European Medicines Agency (EMA) require that patients are tested for KRAS hotspot mutations prior to anti-EGFR treatment using the approved drugs, panitumumab and cetuximab. However, evidence is present that patients harboring the codon 13 c.38 G > A mutation may benefit from antiEGFR treatment $[4,5]$.

We have recently evaluated several methods for the detection of KRAS mutations in clinical samples. The frequency of mutated samples was found to be influenced by the analytical sensitivity of the method applied [6]. In particular, conventional PCR followed by high-resolution melting (HRM) or sequencing failed to detect mutations in a substantial number of samples due to the limited sensitivity of this approach. This may, in part, be caused by intra tumor heterogeneity and contamination with wild-type DNA from normal cells, which typically are observed in infiltrating cancers. We also evaluated a commercially available kit, the TheraScreen ${ }^{\circledR}$ KRAS mutation kit (QIAGEN, Hilden, Germany), and an assay based on fast COLD-PCR, which enriches for mutant sequences by using a lower denaturation temperature in the PCR [7]. These methods are more sensitive, and were capable of identifying additional mutated samples not detected by conventional PCR. However, fast COLD-PCR failed to increase the sensitivity of melting temperature retaining mutations, and the TheraScreen kit is more timeconsuming and less cost-effective compared to HRM followed by sequencing of positive samples [8].

Therefore, we have developed a new method, Competitive Amplification of Differentially Melting Amplicons (CADMA), which enables very sensitive mutation detection regardless of the melting properties of the mutations to be detected [9].

In this contribution, we have designed and optimized CADMA assays for the seven most common KRAS exon 2 hotspot mutations. The sensitivity and specificity of each assay were evaluated using serial dilutions of cell line DNA containing the relevant mutations in a wildtype background. We further evaluated the potential of these assays for the detection of KRAS mutations in CRC samples derived from formalin fixed paraffin embedded (FFPE) tissues. In total, we have tested 100 samples using the CADMA assays, and compared these results with results obtained using the TheraScreen ${ }^{\circledR}$ KRAS mutation kit, which tests for the same seven mutations. Samples, which did not give the same result by CADMA and the TheraScreen kit, were tested using a previously published highly sensitive TaqMan based assay [10] and by fast COLD-PCR followed by Sanger sequencing.

\section{Methods}

\section{Samples and DNA extraction}

Formalin-Fixed Paraffin Embedded (FFPE) blocks from surgical biopsies from 100 patients diagnosed with adenocarcinoma in colon were selected from the archives at the Department of Pathology, Aarhus University Hospital. The specimens were up to 10 years old. For each sample, six tissue sections of $10 \mu \mathrm{m}$ were used for DNA extraction. Deparaffinization and DNA extraction were performed as previously described [6].

DNA from peripheral blood (PB) obtained from medical students were used as wild-type controls. The DNA was extracted following a modified salt precipitation protocol as previously described [11]. The DNA was taken from a biobank for which informed consent was provided for each sample. The approval by the regional ethics comity has the journal number 2001-2.0/37.

The Local Ethical Committee, Aarhus County, Denmark, approved this study.

\section{Cell lines and dilution series}

Seven different cell lines each containing different KRAS mutations were used in this study; A549 (c.34 G > A, codon 12), DLD-1 (c.38 G > A, codon 13), LS174T (c.35 G > A, codon 12), NCI-H23 (c.34 G > T, codon 12) PSN-1 (c.34 G > C, codon 12), RPMI 8226 (c.35 G > C, codon 12), and SW480 (c.35 G > T, codon 12). The cell lines were cultured and harvested, and the DNA was extracted as described [6], with the exception of PSN-1 for which extracted DNA was purchased from Health Protection Agency Culture Collection, UK, and NCIH23 for which extracted DNA was kindly donated by Professor Dmitri Loukinov, NIAID/NIH.

DNA from each cell line was quantified using a NanoDrop ND-1000 spectrophotometer (NanoDrop Technologies, Wilmington, DE) and serially diluted into wild-type DNA to the following fractions of mutated alleles in a wild-type background; $50 \%, 10 \%, 1 \%$, and $0.5 \%$ (assuming no pipetting errors and that all cell lines are monoclonal).

\section{CADMA primer design}

The primer sequences were designed to target the KRAS sequence obtained from GenBank [http://www.ncbi.nlm. nih.gov/GenBank/] (KRAS GenBank accession number NM_033360.2). Mutation specific primers were designed 
for the seven most common KRAS exon 2 mutations. These primers each introduce two melting temperature decreasing mutations. The overlapping primer and the common primer were designed to avoid pseudogene amplification and were the same for all assays. The primers for detection of the c.35 $\mathrm{G}>\mathrm{C}$ mutation has been published previously [9]. Primer sequences can be found in Table 1.

\section{PCR and HRM Conditions for the CADMA assays}

PCR cycling and HRM analysis were performed on the Rotor-Gene 6000 ${ }^{\mathrm{TM}}$ (Corbett Research, Sydney, Australia) or the Rotorgene Q (Qiagen, Hilden, Germany). SYTO ${ }^{\circledR}$ 9 (Invitrogen, Eugene, USA) was used as intercalating dye. The final reaction mixtures consisted of $50 \mathrm{ng}$ of DNA, 1x PCR buffer, $2.5 \mathrm{mmol} / \mathrm{L} \mathrm{MgCl}_{2}$, optimized relative primer concentrations (Table 1), $200 \mu \mathrm{mol} / \mathrm{L}$ of each dNTP, $5 \mu \mathrm{mol} / \mathrm{L}$ of SYTO ${ }^{\circledR}$ 9, 0.5U of HotStarTaq (Qiagen) $(5 \mathrm{U} / \mu \mathrm{L})$ in a volume of $20 \mu \mathrm{L}$. The CADMA cycling protocol was initiated by one cycle at $95^{\circ} \mathrm{C}$ for $15 \mathrm{~min}$, followed by 45 cycles of $95^{\circ} \mathrm{C}$ for $10 \mathrm{~s}$, annealing temperature $\left(\mathrm{T}_{\mathrm{A}}\right)$ for $20 \mathrm{~s}$ (Table 1 ), $72^{\circ} \mathrm{C}$ for $20 \mathrm{~s}$, and one cycle at $95^{\circ} \mathrm{C}$ for $1 \mathrm{~min}$. HRM was performed from $65^{\circ} \mathrm{C}$ to $95^{\circ} \mathrm{C}$ with a temperature increase of $0.1^{\circ} \mathrm{C} / \mathrm{s}$. Samples were analyzed in triplicates (cell line experiments) or in duplicates (colorectal cancer specimens).

\section{CADMA data analysis}

The Rotorgene 6000 Series Software version 1.7.87 supplied with the instrument was used to analyze the data. When analyzing the mCRC samples, standards containing 1\% mutant alleles were used as cut-off point to facilitate direct comparison with the TheraScreen ${ }^{\circledR}$ kit. The samples were scored manually by visual inspection of the derivative of the raw data (melt curve analysis) and the normalized HRM and difference graphs (high resolution melting analysis). For the difference graphs a wild-type sample was selected as reference. The samples were tested with each of seven CADMA assays, however, when a sample was found to be mutation positive it was not tested using the remaining CADMA assays unless the result was in disagreement with the result provided by the TheraScreen kit.

\section{Mutation analysis using the TheraScreen ${ }^{\circledR} K R A S$ mutation Kit}

The mCRC samples were analyzed using the TheraScreen ${ }^{\circledR}$ $K R A S$ mutation kit (Qiagen). This kit analyzes the mutation status for the seven most commonly found KRAS exon 2 mutations by a technology that combines ARMS ${ }^{\circledR}$ (allele specific PCR) with Scorpions ${ }^{\circledR}$ real-time PCR. The manufacturer has reported the sensitivity to be $1 \%$ mutant alleles in a wild-type background if sufficient DNA input is used.

\section{Alelle-specific PCR (TaqMan)}

The TaqMan based allele-specific PCR assay used herein has been published recently by Lang et al. [10]. We used the same PCR conditions and real-time PCR instrument as described. This assay determines mutation status using a predetermined cutoff $\Delta \mathrm{Ct}$ value (Ct [allele-specific assay] $\mathrm{Ct}$ [reference assay]) as described [10]. The analytical sensitivity of the assays were reported to be $1 \%$ mutant alleles in a wild-type background [10]. Samples were analyzed in duplicates for all TaqMan experiments and the average $\mathrm{Ct}$ value of the duplicates was used to calculate $\Delta \mathrm{Ct}$ values.

\section{COLD-PCR followed by Sanger sequencing}

The COLD-PCR was essentially performed as previously described [6]. However, only 10 standard PCR cycles were performed prior to the COLD-PCR cycles using a critical temperature of $78^{\circ} \mathrm{C}$. Sanger sequencing was performed using M13 tagged primers to create a longer amplicon, which could be successfully sequenced as previously described [6]. The COLD-PCR assay could detect $0.5 \%$ DNA from the A549 cell line diluted in wild-type DNA, and 1\% DNA from the LS174T cell line diluted in wild-type DNA (data not shown).

\section{Results}

The analytical sensitivity of the CADMA assays for the detection of KRAS hotspot mutations

The CADMA assays were optimized to avoid false amplification from wild-type sequences by the mutation specific primer, while maintaining a high sensitivity as previously described [9]. Hereafter, the sensitivity and specificity was evaluated by analyzing ten wild-type replicates together with a standard dilution series of mutant alleles into wild-type alleles $(50 \%, 10 \%, 1 \%$, and $0.5 \%)$ in triplicates. All three replicates of the $0.5 \%$ standard could be distinguished from all ten wild-type replicates in all assays (Figure 1).

To assess in between run variation, we repeated each of these experiments using the Rotorgene Q (Qiagen, Hilden, Germany) in a different laboratory. Again, the three replicates of the $0.5 \%$ standard could all be distinguished from ten wild-type replicates in all assays, and no false amplification in wild-type reactions was observed (Additional file 1: Figure S1).

\section{KRAS hotspot mutation analysis in CRC samples using} CADMA and the TheraScreen ${ }^{\circledR}$ KRAS mutation Kit One-hundred mCRC samples derived from FFPE tissues were analyzed for KRAS mutations using the CADMA assays and the TheraScreen ${ }^{\circledR}$ kit. One and 
Table 1 Details of the CADMA assays

\begin{tabular}{|c|c|c|c|c|}
\hline Mutation & Cell line & Primers (introduced mutations are underlined) & Primer concentrations & Annealing temperature \\
\hline \multirow[t]{6}{*}{ c.34 G > A } & A549 & Mutation specific forward: & $400 \mathrm{nM}$ & $57^{\circ} \mathrm{C}$ \\
\hline & & GAATATAAACTTÁTGGTAGTTGGAGA-ATA & & \\
\hline & & Overlapping forward: & $100 \mathrm{nM}$ & \\
\hline & & ATGACTGAATATAAACTTGTGGTAGTTG & & \\
\hline & & Common reverse: & $400 \mathrm{nM}$ & \\
\hline & & ACTGTCAAGGCACTCTTGCCTAC & & \\
\hline \multirow[t]{6}{*}{ c.34 G > T } & $\mathrm{NCl}-\mathrm{H} 23$ & Mutation specific forward: & $400 \mathrm{nM}$ & $60^{\circ} \mathrm{C}$ \\
\hline & & GAATATAAACTTGTAGTAATTGGAGCTT & & \\
\hline & & Overlapping forward: & $150 \mathrm{nM}$ & \\
\hline & & ATGACTGAATATAAACTTGTGGTAGTTG & & \\
\hline & & Common reverse: & $400 \mathrm{nM}$ & \\
\hline & & ACTGTCAAGGCACTCTTGCCTAC & & \\
\hline \multirow[t]{6}{*}{ c.34 G > C } & PSN1 & Mutation specific forward: & $400 \mathrm{nM}$ & $60^{\circ} \mathrm{C}$ \\
\hline & & GAATATAAACTTGTAGTAAITTGGAGCTC & & \\
\hline & & Overlapping forward: & $100 \mathrm{nM}$ & \\
\hline & & ATGACTGAATATAAACTTGTGGTAGTTG & & \\
\hline & & Common reverse: & $400 \mathrm{nM}$ & \\
\hline & & ACTGTCAAGGCACTCTTGCCTAC & & \\
\hline \multirow[t]{6}{*}{ c. $35 \mathrm{G}>\mathrm{A}$} & LS174T & Mutation specific forward: & $400 \mathrm{nM}$ & $60^{\circ} \mathrm{C}$ \\
\hline & & GAATATAAACTTGTGGTAATTGGAGATGA & & \\
\hline & & Overlapping forward: & $150 \mathrm{nM}$ & \\
\hline & & ATGACTGAATATAAACTTGTGGTAGTTG & & \\
\hline & & Common reverse: & $400 \mathrm{nM}$ & \\
\hline & & ACTGTCAAGGCACTCTTGCCTAC & & \\
\hline \multirow[t]{6}{*}{ c.35 G > T } & SW480 & Mutation specific forward: & $400 \mathrm{nM}$ & $64^{\circ} \mathrm{C}$ \\
\hline & & GAATATAAACTTGTAGGTAATTGGAGCTGT & & \\
\hline & & Overlapping forward: & $150 \mathrm{nM}$ & \\
\hline & & ATGACTGAATATAAACTTGTGGTAGTTG & & \\
\hline & & Common reverse: & $400 \mathrm{nM}$ & \\
\hline & & ACTGTCAAGGCACTCTTGCCTAC & & \\
\hline \multirow[t]{6}{*}{ c. $35 \mathrm{G}>\mathrm{C}$} & RPMI8226 & Mutation specific forward: & $400 \mathrm{nM}$ & $58^{\circ} \mathrm{C}$ \\
\hline & & GAATATAAACTTGTAGGTAATTGGAGCTGC & & \\
\hline & & Overlapping forward: & $100 \mathrm{nM}$ & \\
\hline & & ATGACTGAATATAAACTTGTGGTAGTTG & & \\
\hline & & Common reverse: & $400 \mathrm{nM}$ & \\
\hline & & ACTGTCAAGGCACTCTTGCCTAC & & \\
\hline \multirow[t]{6}{*}{ c. $38 \mathrm{G}>\mathrm{A}$} & DLD-1 & Mutation specific forward: & $400 \mathrm{nM}$ & $62^{\circ} \mathrm{C}$ \\
\hline & & AAACTTGTGGTAGTTGGAGATGGTIA & & \\
\hline & & Overlapping forward: & $150 \mathrm{nM}$ & \\
\hline & & ATGACTGAATATAAACTTGTGGTAGTTG & & \\
\hline & & Common reverse: & $400 \mathrm{nM}$ & \\
\hline & & ACTGTCAAGGCACTCTTGCCTAC & & \\
\hline
\end{tabular}



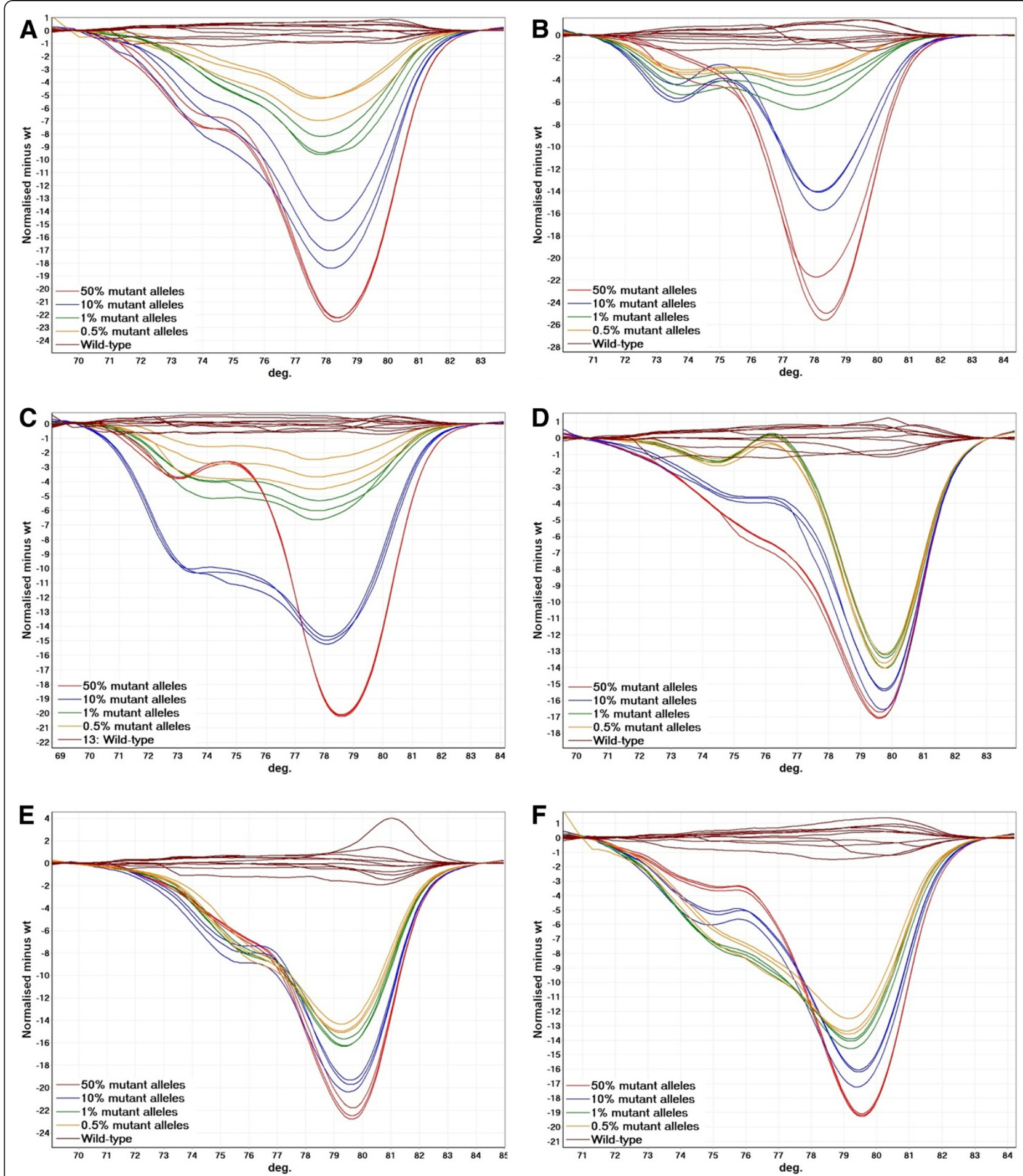

Figure 1 The analytical sensitivity and specificity of the CADMA assays performed using the Rotorgene 6000 . Ten wild-type replicates were run together with a standard dilution series of mutant alleles from cell lines carrying the relevant mutations in a wild-type background $(50 \%, 10 \%, 1 \%$, and $0.5 \%)$ in triplicates. The three replicates of the $0.5 \%$ standard could all be distinguished from ten wild-type replicates in all assays. A. The c.34 G > A CADMA assay. B. The c.38 G > A CADMA assay. C. The c.35 G > A CADMA assay. D. The c.34 G > C CADMA assay. E. The c.35 G > T CADMA assay. F. The c.34 G > T CADMA assay. 
two samples failed to amplify, when using CADMA and the TheraScreen ${ }^{\circledR}$ kit, respectively. These samples were scored as "no data". Using the TheraScreen kit 45/98 (45.9\%) of the samples were found to carry a KRAS exon 2 mutation. Using CADMA 44/99 (44.4\%) of the samples were mutation positive. Consensus between the two methods was found in 93/97 (95.9\%) of the samples. The results are summarized in Additional file 2: Table S1.

Examples from the c.34 G > T CADMA assay are shown in Figure 2. Since the overlapping CADMA primer amplifies both mutated and wild-type sequences each CADMA assay may detect KRAS mutations other than the one targeted by the mutation specific primer albeit at a lower sensitivity. The shape of the melting curves could easily be used to distinguish the mutation, targeted by each CADMA assay, from other mutations detected by the overlapping primer, as the resulting amplicons have different melting properties, due to the two additional mutations incorporated by the mutation specific primer. Examples of this are shown in Figure 2. When samples amplify late this may cause the melting curves to be shifted [12], and other abnormalities, such as the one shown for sample ID 69 in Figure 2, may also result in deviations of the melting curves. Shifted melting curves may result in differences in the normalized HRM and difference graphs, which could lead to wrong interpretation of the results, if the melting curves are not inspected.

When testing DNA samples derived from FFPE tissues more variation in the melt curves is likely to be observed compared to DNA samples of high quality [9]. For this reason, it is also important to analyze the samples of unknown mutation status relative to standards of known ratios of wild-type to mutant alleles. Generally, the wild-type samples showed more variation in the c.38 G > A CADMA assay compared to any of the other CADMA assays (Figure 3). However, this did not give rise to misclassification of any of the samples, and the wild-type status of sample ID 10 and 12 shown in figure 3 could be confirmed by COLD-PCR followed by sequencing (data not shown). However, sample ID 2 was shown to contain a c. $37 \mathrm{G}>\mathrm{A}$ and a c. $39 \mathrm{C}>$ $\mathrm{G}$ mutation, which are not tested for by the TheraScreen kit and CADMA. These mutations are likely to be present at very low levels as they were found only when sequencing in the forward direction, or alternatively they may be sequencing errors.

\section{Confirmation of the CADMA results by TaqMan and by COLD-PCR followed by sequencing}

The four samples, not providing the same result for both methods, were tested using a previously published TaqMan based assay [10] and by fast COLD-PCR followed by sequencing. For sample ID 73 the TheraScreen kit was positive for the c.35 G > A mutation, and negative by CADMA. Sample ID 65 was positive for the c.34 $\mathrm{G}>\mathrm{A}$ mutation and the c. $35 \mathrm{G}>\mathrm{C}$ mutation by the TheraScreen kit, and only positive for the c.35 G > C mutation by CADMA. Sample ID 91 was positive for the c.35 $\mathrm{G}>\mathrm{A}$ mutation by the TheraScreen kit and the c.38 G > A as well as the c.35 G > A mutation by CADMA. Finally, sample ID 96 was positive for the c.34 $\mathrm{G}>\mathrm{T}$ mutation by the TheraScreen kit and the c.34 $\mathrm{G}>\mathrm{T}$ and c.35 $\mathrm{G}>\mathrm{A}$ mutations by CADMA. The CADMA results were confirmed by the TaqMan assay for all four samples. When using the COLD-PCR assay the CADMA and TaqMan results were confirmed for sample ID 65, 73, and 96. In sample ID 91, the c. 38 G $>$ A mutation detected by CADMA and TaqMan was confirmed, however, the c.35 G > T mutation detected by CADMA, TaqMan, and the TheraScreen kit was not detected by COLD-PCR (Additional file 2: Table S1).

\section{Discussion}

Screening for well-characterized point mutations predicting response or non-response to targeted therapies has in recent years become widely implemented in clinical settings. However, conventional PCR followed by Sanger sequencing, pyrosequencing, or HRM analysis may often fail to identify mutations in samples with a substantial wild-type DNA content $[6,13,14]$. It has also been shown that increased detection sensitivity may be used to identify additional patients which do not respond to anti-EGFR treatment [14]. For this reason, there is an increasing need for sensitive, reliable, and cost-effective methods for the detection of known mutations.

We have developed assays for detection of the seven most common KRAS mutations based on our recently developed method named Competitive Amplification of Differentially Melting Amplicons (CADMA), which may be combined with COLD-PCR to further increase the sensitivity of the assay [9]. However, clinical decision making based upon very low prevalence KRAS mutations is controversial, as it has not yet been clarified how mutation heterogeneity within CRC tumours affects outcome in patients treated with EGFR antibodies. Therefore, we decided not to combine the CADMA assays with COLD-PCR in the present study. Nevertheless, the analytical sensitivities of all assays were at least $0.5 \%$ mutant alleles in a wild-type background. These results were confirmed in another laboratory. However, it could be observed that the separation between the cell line dilutions and the wild-types were more pronounced in some runs than others, indicating that some in between run variation may occur. In between run variation is most likely to be caused by varying primer concentrations in the master mixes, which were 

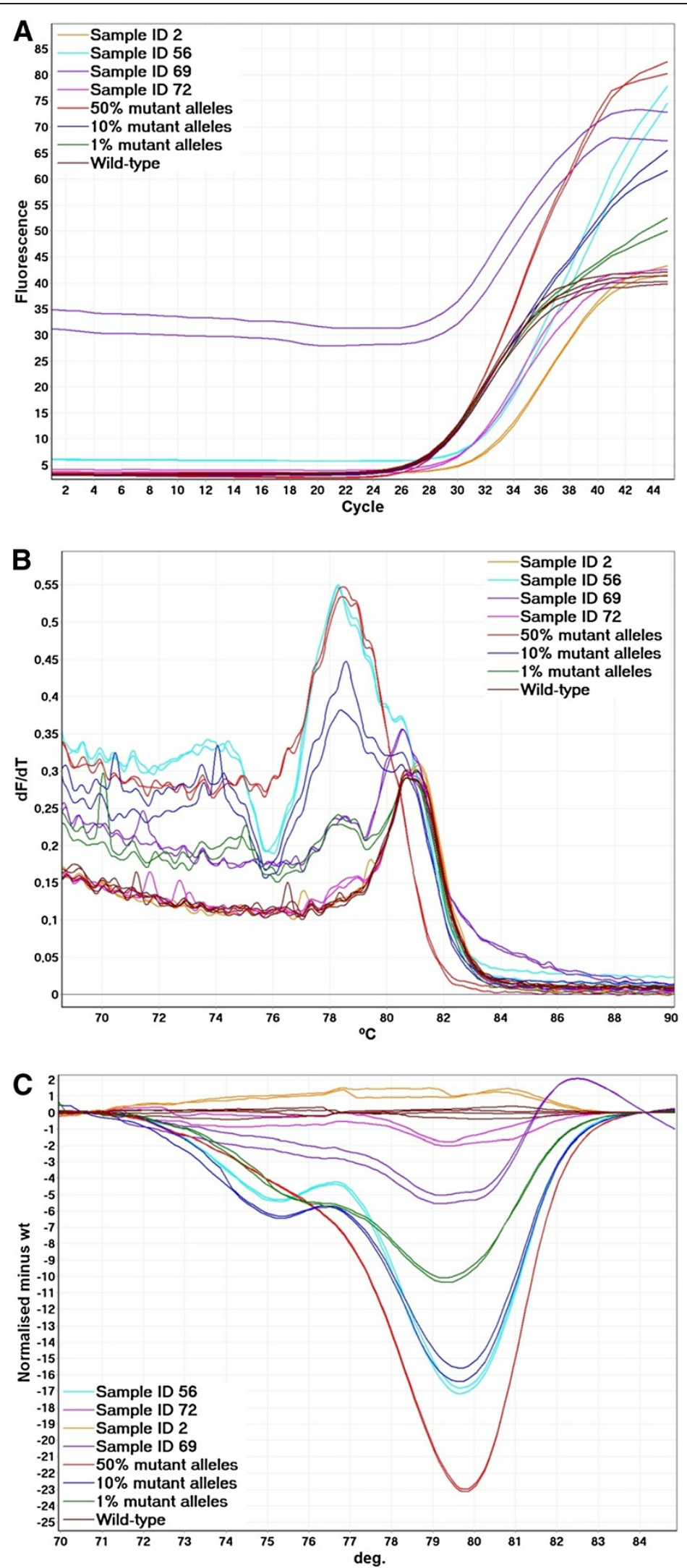

Figure $\mathbf{2}$ (See legend on next page.) 
(See figure on previous page.)

Figure 2 Examples from screening of mCRC samples using the c.34 G > T CADMA assay. A. Real-time amplification data. High background fluorescence can be observed for sample ID 69. B. The derivative of the raw melting data (melt curve analysis). Sample ID 56 carry the C.34 G > T mutation. Sample ID 2, 69 and 72 were negative for the c.34 G > T mutation. Sample ID 69 and 72 may carry another KRAS mutation as small deviations from the wild-type replicates can be observed. Sample ID 69, which gave high fluorescence during the PCR amplification, has deviating melt curves from 82 to $88^{\circ} \mathrm{C}$. C. Normalized HRM difference graph. Of the mCRC samples shown only one (sample ID 56) deviates more from the wild-type replicates than the standard containing $1 \%$ mutant alleles.

prepared on a run to run basis, or variation caused by the instruments.

We did not assess the analytical sensitivity of the commercially available TheraScreen kit, which has been reported by the company to be sensitive to $1 \%$ mutant alleles in a wild-type background. However, it has been reported that diagnostic samples derived from FFPE tissues often may not be analyzed at this level of sensitivity [15]. Nevertheless, we have recently shown that the TheraScreen kit can detect mutations in samples derived from FFPE tissues, which could not be detected by conventional PCR followed by HRM or sequencing [6].

Here, we have analyzed mCRC samples from 100 patients using the TheraScreen kit and the CADMA assays. To facilitate direct comparison between the two methods, the samples were analyzed at $1 \%$ mutant level when using CADMA. Overall, consensus between the two methods was very high (95.9\%), and in four out of four cases where different results were observed, the CADMA result could be confirmed by a previously published TaqMan based assay, which is sensitive to about $1 \%$ mutant alleles in a wild-type background [10], and by COLD-PCR followed by Sanger sequencing. However, in one sample a mutation detected by CADMA,
TaqMan, and the Therascreen kit was not detected by COLD-PCR. Therefore, it is likely that the TheraScreen kit gave false positive results in two cases (c.34 G > A in sample ID 65 and c.35 G > A in samples ID 73) and false negative results in two cases (c.38 G > A in sample ID 91 and c.35 G > A in sample ID 96). Nevertheless, mCRC patients are pro tem only classified as mutation positive or negative for selection of treatment groups. Therefore, only one (sample ID 73) of the 100 patients studied is likely to have been misclassified. However, as previously mentioned, evidence is now present that patients harboring the codon 13 c.38 G > A mutation may benefit from anti-EGFR treatment $[4,5,14]$. False positive and negative results have previously been observed when using the TheraScreen kit in the order $1-2 \%$ [16].

We used 50 ng of DNA in the reactions, but it is likely that the CADMA assays will perform equally well using $25 \mathrm{ng}$ or less DNA, which we have shown in a study of $B R A F$ mutations in FFPE cutaneous malignant melanoma samples [13].

Many different methods have been developed with the goal of increasing the analytical sensitivity of mutation testing, however, increased sensitivity often comes with the cost of lower accuracy, increased complexity, and
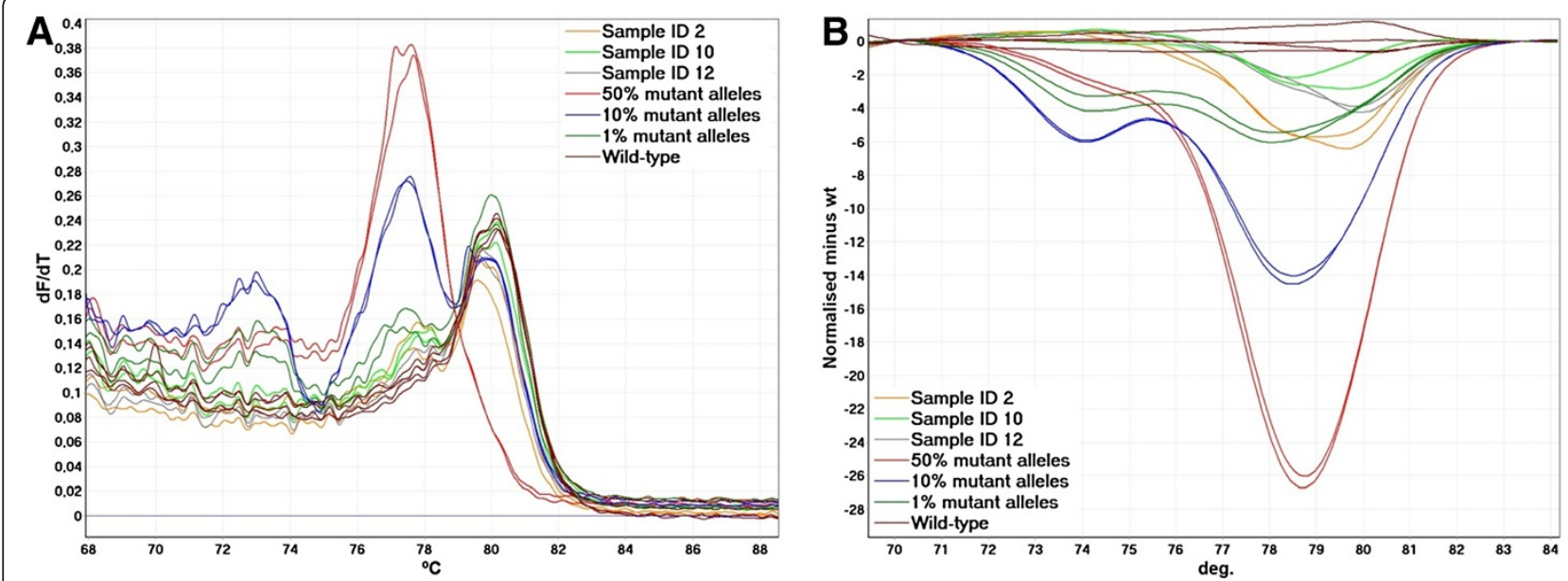

Figure 3 Examples from screening of mCRC samples using the c.38 G > T CADMA assay. The wild-type mCRC samples showed more variation in the c.38 G > A CADMA assay compared to any of the other CADMA assays. A. The derivative of the raw melting data (melt curve analysis). No heteroduplexes, which melt between 71 and $74^{\circ} \mathrm{C}$, can be observed in any of the wild-type mCRC samples. B. Normalized HRM difference graph. Sample ID 2 deviates more from the wild-type replicates than the standard containing $1 \%$ mutant alleles from approximately 79 to $81^{\circ} \mathrm{C}$. This should not be interpreted as a c.38 G > T mutation, since no heteroduplexes are present. 
higher costs [17]. The TheraScreen kit uses a combination of mutation specific PCR primers and Scorpion probes, and is relatively expensive and labor-intense compared to most other methods employed for KRAS mutation detection [8]. CADMA uses HRM analysis to determine mutation status, which can be performed in a closed tube format without the use of any labeled oligonucleotides. HRM has been used for a range of different applications in molecular diagnostics due to its costeffectiveness and convenience [18]. Compared to the TheraScreen kit and the TaqMan based assay, CADMA does not require a control assay as the real-time PCR data serves as a control for the quality of the sample, and thus the mutation status can be determined directly after a single run. However, scoring the samples of unknown mutation status is not always straightforward as visual inspection of both the derivative of the raw data (melt curve analysis) and the normalized HRM and difference graphs (high resolution melting analysis) may be needed for correct interpretation of the melting data.

The CADMA assays presented here have not been optimized to perform at a specific annealing temperature, which would have been an advantage as one sample then could be tested for all seven mutations in a single run. However, this may be achieved by changing the concentration of the overlapping primer and/or by designing new mutation specific primers. Incorporation of locked nucleic acids (LNAs) in the mutation specific primers may also make this task easier as the temperature window, where the mutation specific primer distinguish well between mutated and wild-type sequences, may be expanded. It may also be possible to multiplex CADMA assays while still being able to distinguish between different mutations, if one mutation specific primer introduces melting temperature decreasing mutations in the resulting mutated amplicon, and another mutation specific primer introduces melting temperature increasing mutations in the other resulting mutated amplicon.

The possibility to detect low or moderate abundance mutations is important in many different aspects of molecular diagnostics [19]. The mutation to be detected is often well characterized as is the case for KRAS mutations and other mutations in genes such as BRAF, EGFR, and PIK3CA. However, when the mutation to be detected with high sensitivity is unknown, other methods such as COLD-PCR [7] or Ice-COLD-PCR [20] followed by sequencing or pyrosequencing is recommended. IceCOLD-PCR uses a synthetic wild-type-specific oligonucleotide reference sequence (RS), which is slightly shorter than the length of the PCR amplicon, so that it obstructs primer binding, and thereby inhibits amplification of wild-type alleles when using a five step PCR as described [20]. The RS contains a 3'-phosphate modification to prevent polymerase extension, and should be used together with a polymerase that lacks 5'to 3'-exonuclease activity to prevent potential problems by its hydrolysis. The advantage of Ice-COLD-PCR is that the RS can be relatively long compared to the use of short wild-type-blocking oligonucleotides, which can be used without COLD-PCR [21], thereby allowing sensitive screening for unknown mutations of longer DNA sequences. Wild-type-blocking oligonucleotides which contain LNAs have been used to further increase the sensitivity of $B R A F$ and $K R A S$ mutation detection in Wild-type blocking PCR (WTB-PCR) [22,23]. Though WTB-PCR has proven to be highly sensitive, it is not performed in a closed-tube format, as sequencing of the PCR product is necessary.

\section{Conclusions}

In conclusion, CADMA may improve KRAS mutation screening in mCRC. The use of an overlapping primer, which competes with the mutation specific primer for target binding may reduce or eliminate false amplification otherwise often observed in allele-specific PCR. In addition, the robust amplification of samples containing low abundance mutations provided by the overlapping primer may prevent false negative results. CADMA is performed in a closed tube format and mutation status can be determined directly by HRM analysis.

\section{Additional files}

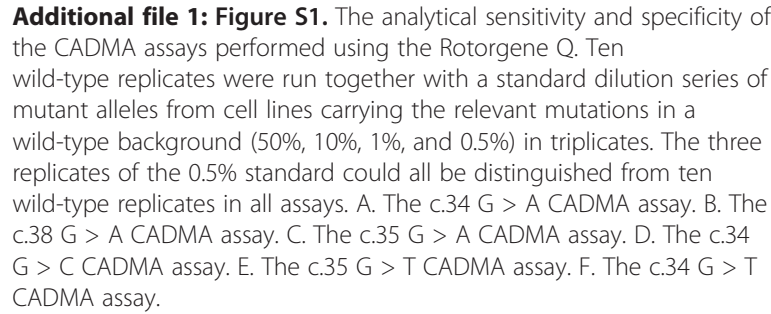

Additional file 1: Figure S1. The analytical sensitivity and specificity of the CADMA assays performed using the Rotorgene Q. Ten wild-type replicates were run together with a standard dilution series of mutant alleles from cell lines carrying the relevant mutations in a wild-type background (50\%, 10\%, 1\%, and $0.5 \%$ ) in triplicates. The three replicates of the $0.5 \%$ standard could all be distinguished from ten wild-type replicates in all assays. A. The c.34 G > A CADMA assay. B. The c.38 G > A CADMA assay. C. The C.35 G > A CADMA assay. D. The c.34 $\mathrm{G}>\mathrm{C}$ CADMA assay. E. The C.35 G> T CADMA assay. F. The c.34 G > T CADMA assay.

Additional file 2: Table S1. Overview of the results from screening 100 mCRC samples using the TheraScreen kit and CADMA. A TaqMan based assay and COLD-PCR followed by sequencing were used to test samples for which the TheraScreen kit and CADMA did not give the same result.

\section{Competing interests}

Aarhus University has filed a patent application concerning the CADMA methodology with Kristensen LS, Hager H, and Hansen LL listed as inventors.

\section{Authors' contributions}

TEK carried out the molecular genetic studies, analysed the data, and co-wrote the manuscript. HH and LLH participated in the study design and co-wrote the manuscript. LSK conceived the study, participated in the study design, analysed the data, and co-wrote the manuscript. All authors read and approved the final manuscript.

\section{Acknowledgements}

Jesper Bertelsen is acknowledged for excellent technical assistance. Professor Dmitri Loukinov kindly donated extracted DNA from the $\mathrm{NCl}-\mathrm{H} 23$ cell line and Professor Stephen Hamilton-Dutoit the CRC specimens used in this 
study. This work was supported by The A.P. Møller and Chastine McKinney Møller Foundation (grant to LSK)

\section{Author details}

'Department of Biomedicine, University of Aarhus, Bartholin Building, Wilhelm Meyers Allé 4, DK-8000 Aarhus C, Denmark. ${ }^{2}$ Department of Pathology, Aarhus University Hospital, Nørrebrogade 45, DK-8000 Aarhus C, Denmark.

Received: 25 June 2012 Accepted: 12 November 2012

Published: 23 November 2012

\section{References}

1. Diamandis M, White NM, Yousef GM: Personalized medicine: marking a new epoch in cancer patient management. Mol Cancer Res 2010, 8(9):1175-1187.

2. Amado RG, Wolf M, Peeters M, Van Cutsem E, Siena S, Freeman DJ, Juan T, Sikorski R, Suggs S, Radinsky R, et al: Wild-type KRAS is required for panitumumab efficacy in patients with metastatic colorectal cancer. I clin Oncol: Off J Am Soc Clin Oncol 2008, 26(10):1626-1634.

3. Lievre A, Bachet JB, Le Corre D, Boige V, Landi B, Emile JF, Cote JF, Tomasic G, Penna C, Ducreux M, et al: KRAS mutation status is predictive of response to cetuximab therapy in colorectal cancer. Cancer Res 2006, 66(8):3992-3995.

4. De Roock W, Jonker DJ, Di Nicolantonio F, Sartore-Bianchi A, Tu D, Siena S, Lamba S, Arena S, Frattini M, Piessevaux H, et al: Association of KRAS p. G13D mutation with outcome in patients with chemotherapy-refractory metastatic colorectal cancer treated with cetuximab. JAMA: J Am Med Assoc 2010, 304(16):1812-1820.

5. Martini M, Vecchione L, Siena S, Tejpar S, Bardelli A: Targeted therapies: how personal should we go? Nat rev Clin Oncol 2012, 9(2):87-97.

6. Kristensen LS, Daugaard IL, Christensen M, Hamilton-Dutoit S, Hager H, Hansen LL: Increased sensitivity of KRAS mutation detection by high-resolution melting analysis of COLD-PCR products. Hum Mutat 2010, 31(12):1366-1373

7. Li J, Wang L, Mamon H, Kulke MH, Berbeco R, Makrigiorgos GM: Replacing PCR with COLD-PCR enriches variant DNA sequences and redefines the sensitivity of genetic testing. Nat Med 2008, 14(5):579-584.

8. Whitehall V, Tran K, Umapathy A, Grieu F, Hewitt C, Evans TJ, Ismail T, Li WQ, Collins P, Ravetto P, et al: A multicenter blinded study to evaluate KRAS mutation testing methodologies in the clinical setting. $J$ mol diagn: JMD 2009, 11(6):543-552.

9. Kristensen LS, Andersen GB, Hager H, Hansen LL: Competitive amplification of differentially melting amplicons (CADMA) enables sensitive and direct detection of all mutation types by high-resolution melting analysis. Hum Mutat 2012, 33(1):264-271.

10. Lang AH, Drexel H, Geller-Rhomberg S, Stark N, Winder T, Geiger K, Muendlein A: Optimized allele-specific real-time PCR assays for the detection of common mutations in KRAS and BRAF. J Mol diagn: JMD 2011, 13(1):23-28.

11. Hansen LL, Andersen J, Overgaard J, Kruse TA: Molecular genetic analysis of easily accessible breast tumour DNA, purified from tissue left over from hormone receptor measurement. APMIS 1998, 106(3):371-377.

12. Kristensen $L S$, Dobrovic A: Direct genotyping of single nucleotide polymorphisms in methyl metabolism genes using probe-free highresolution melting analysis. Cancer epidemiol, biomark \& prev: pub Am Assoc Cancer Res, cospons Am Soc Prev Oncol 2008, 17(5):1240-1247.

13. Lade-Keller J, Munck KR, Guldberg P, Riber-Hansen R, Hansen LL, Steiniche T, Hager $\mathrm{H}$, Kristensen LS: Evaluation of BRAF Mutation Testing Methodologies in Formalin Fixed Paraffin Embedded (FFPE) Cutaneous Melanomas. J Mol Diagnost 2012, in press.

14. Molinari F, Felicioni L, Buscarino M, De Dosso S, Buttitta F, Malatesta S, Movilia A, Luoni M, Boldorini R, Alabiso O, et al: Increased detection sensitivity for KRAS mutations enhances the prediction of anti-EGFR monoclonal antibody resistance in metastatic colorectal cancer. Clin cancer res: off j Am Assoc Cancer Res 2011, 17(14):4901-4914.

15. Kotoula V, Charalambous E, Biesmans B, Malousi A, Vrettou E, Fountzilas G, Karkavelas G: Targeted KRAS mutation assessment on patient tumor histologic material in real time diagnostics. PLoS One 2009, 4(11):e7746

16. Tol J, Dijkstra JR, Vink-Borger ME, Nagtegaal ID, Punt CJ, Van Krieken JH, Ligtenberg MJ: High sensitivity of both sequencing and real-time PCR analysis of KRAS mutations in colorectal cancer tissue. $J$ cell mol med 2010, 14(8):2122-2131.

17. Milbury CA, Li J, Makrigiorgos GM: PCR-based methods for the enrichment of minority alleles and mutations. Clin Chem 2009, 55(4):632-640.

18. Wittwer CT: High-resolution DNA melting analysis: advancements and limitations. Hum Mutat 2009, 30(6):857-859.

19. Milbury CA, Li J, Liu P, Makrigiorgos GM: COLD-PCR: improving the sensitivity of molecular diagnostics assays. Expert Rev Mol Diagn 2011, 11(2):159-169.

20. Milbury CA, Li J, Makrigiorgos GM: Ice-COLD-PCR enables rapid amplification and robust enrichment for low-abundance unknown DNA mutations. Nucleic Acids Res 2011, 39(1):e2.

21. Yu D, Mukai M, Liu Q, Steinman CR: Specific inhibition of PCR by nonextendable oligonucleotides using a $5^{\prime}$ to $3^{\prime}$ exonuclease-deficient DNA polymerase. Biotechniques 1997, 23(4):714-716. 718-720.

22. Dominguez PL, Kolodney MS: Wild-type blocking polymerase chain reaction for detection of single nucleotide minority mutations from clinical specimens. Oncogene 2005, 24(45):6830-6834.

23. Huang Q, Wang GY, Huang JF, Zhang B, Fu WL: High sensitive mutation analysis on KRAS gene using LNA/DNA chimeras as PCR amplification blockers of wild-type alleles. Mol cell probes 2010, 24(6):376-380.

\section{doi:10.1186/1471-2407-12-548}

Cite this article as: Kristensen et al:: Competitive amplification of differentially melting amplicons (CADMA) improves KRAS hotspot mutation testing in colorectal cancer. BMC Cancer 2012 12:548.

\section{Submit your next manuscript to BioMed Central and take full advantage of:}

- Convenient online submission

- Thorough peer review

- No space constraints or color figure charges

- Immediate publication on acceptance

- Inclusion in PubMed, CAS, Scopus and Google Scholar

- Research which is freely available for redistribution

Submit your manuscript at www.biomedcentral.com/submit
C Biomed Central 